\title{
Tackling serum folate test in European countries within the health technology assessment paradigm: request appropriateness, assays and health outcomes
}

DOI 10.1515/cclm-2016-0804

Received September 7, 2016; accepted November 7, 2016; previously published online December 19, 2016

\begin{abstract}
Several authors have recently claimed an excess in serum folate test ordering, suggesting phasing out it from clinical use. According to studies performed in countries undergoing folic acid fortification policies, it is indeed no more cost-effective to test folate in the face of deficiency prevalence $<1 \%$. In this paper, we sought to evaluate request appropriateness, analytical issues, and cost-effectiveness of serum folate determination for clinical purposes in the European context, considering if evidence retrieved in fortified countries may be generalized. Studies performed in non-fortified countries have generally reported a suboptimal folate intake and suggest a remarkable prevalence of folate deficiency. Our internal data suggest that $\sim 20 \%-25 \%$ of the subjects undergoing serum folate test are at risk for deficiency. However, a reliable evaluation of the risk for deficiency implies the knowledge of all issues related to the total testing process of folate measurement as well as the identification of the appropriate population in which to perform the test. The cost-effectiveness of the test is maximized when the request is oriented to subjects suggestive/at risk for deficiency, becoming low if the test is used as a screening tool or for monitoring of vitamin intake/supplementation. Because the individual folate status has a key role
\end{abstract}

\footnotetext{
*Corresponding author: Simona Ferraro, UOC Patologia Clinica, Ospedale 'Luigi Sacco', Via G.B. Grassi 74, 20157 Milan, Italy, Phone: +39 023904 2766, Fax: +3902 50319835,

E-mail: simona.ferraro@asst-fbf-sacco.it

Andrea Panzeri: Research Centre for Metrological Traceability in Laboratory Medicine (CIRME), University of Milan, Milan, Italy Mauro Panteghini: Clinical Pathology Unit, University Hospital 'Luigi Sacco', Milan, Italy; and Research Centre for Metrological Traceability in Laboratory Medicine (CIRME), University of Milan, Milan, Italy
}

in ensuring normal development, physiologic growth, and maintenance of optimal health, the evaluation of its serum levels has to be retained in the clinical use in non-fortified countries, boosting for more appropriate request, and evidence from countries following fortification policies should be cautionary interpreted.

Keywords: assay; biological variability; folate; request; traceability.

\section{Introduction}

Recently, several authors have debated the utility of serum folate testing, also in face of the high rate of misuse and of the associated costs [1-5]. From the retrospective analysis of data, a shared position on the utility and cost-effectiveness of folate testing has emerged. The main evidence is well summarized in the systematic review by the Canadian Agency for Drugs and Technologies in Health (CADTH) [6], showing that the folate test is highly requested, but its results do not affect the clinical management of patients, thus resulting in a poor cost-effectiveness [7-9]. The CADTH report is well rooted on the evidence mainly built on American/Australian populations, characterized by a far low prevalence of folate deficiency (ranging from 0.1 to $1 \%$ ) due to wheat flour folate fortification $[6,10,11]$. Nevertheless, appraisals claim that the rate of folate testing has not significantly changed after fortification to yield a significant shrinkage of costs, although indications for the appropriateness of the request have been clearly reported $[6,12]$.

Although folate testing in subjects without known risk factors has little clinical significance [13], a wide range of conditions have been identified all potentially impairing folate intake/absorption or increasing requirement (Table 1) [5, 6, 14-17]. For many of these risk conditions, a poor clinical utility of folate testing has, however, been reported, since patients usually exhibit serum 
Table 1: Conditions potentially impairing folate intake/absorption or increasing requirement.

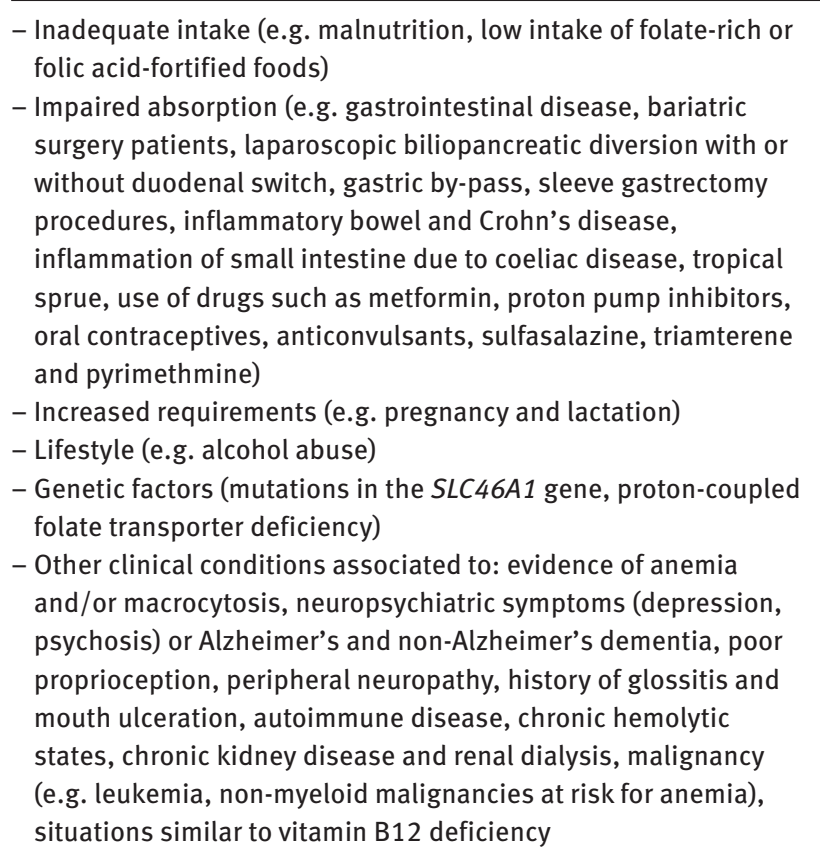

concentrations well within the reference interval, and this is true in non-fortified countries too $[5,18,19]$.

Several US authors are now seeking for phase out folate testing according to the mentioned evidence of low utility and poor cost-effectiveness for both inpatients and outpatients $[1,4,20]$. It is also noteworthy that for several populations of individuals at risk for deficiency, folic acid supplementation is highly recommended or suggested, but folate testing is not required or is not accounted for prior initiating supplementation $[8,9]$. Furthermore, it has been reported that the knowledge of low folate results often does not change the clinical management of patients [6]. This is fostered by the lack of evidence on the benefit associated to or consequent to folate testing $[1,6,20]$. On the other hand, it has been shown that the direct costs of folate testing overcome those of supplementation, which is not associated to side effects apart from masking hematological symptoms of vitamin $B_{12}$ deficiency with exacerbation of neurological symptoms [9].

In 2000, a European document focused on the tolerable upper intake level of folate, alerting that the excess of synthetic folic acid supplementation may increase the concentration of unmetabolized folic acid (UMFA). The accumulation of both vitamers may result in various adverse outcomes, such as epileptogenic and neurotoxic effects, decreased efficacy of some chemotherapeutics, decreased zinc absorption and deficiency, and carcinogenicity [2123]. More recently, other authors wholly disagreed with these warnings, observing that the relationship of folic acid with adverse effects can be affected by several confounding factors [24]. For instance, the hypothesis of an association of folic acid supplementation with cancer development is rapidly declining, owing to its possible chemopreventive role and no evidence of a relationship with cancer incidence [24, 25]. Currently, the main indication on a possible adverse effect of folic acid upper intake level addresses the surveillance of the elderly for what concerns the possible masking of a vitamin $\mathrm{B}_{12}$ deficit [21]. Any possible effect of blood UMFA on health remains to be elucidated, and this is not an easy task, considering that folate assays available for clinical purposes are not able to detect it [26].

Considering the above-described premise, it seems appropriate to review here the cost-effectiveness of serum folate determination for clinical purposes in the European context, considering if the evidence retrieved in countries undergoing mandatory folic acid fortification policy may be generalized to other countries and the related pipeline shared.

\section{Folate testing to quote risk for deficiency in Europe: a public health problem}

\section{Evidence from European countries}

Although the CADTH report represents the most recent and exhaustive review on optimal methods for folate testing, its clinical utility, cost-effectiveness, and appropriateness of the request, in Europe, we cannot, in principle, rely on recommendations built in folate-fortified countries. Here, the prevalence of folate deficiency is now too low to provide a reliable evidence on the clinical utility of this test. As for all tests used in laboratory medicine, the capability of folate results to correctly identify or exclude a deficiency strongly depends on the prevalence (pretest probability) of the condition in the clinical setting in which the test is applied [27].

A robust and updated estimate of folate deficiency in the European countries is lacking, although several documents have reported on the occurrence and incidence of diseases related to folate deficiency, with strong recommendations on supplementation [28-31]. This concept has recently been reinforced by Mills and Dimopoulos, discussing on the possible introduction of folic acid fortification in Europe and observing that the cost-benefit of this 
policy in US has been shown by the consequent dropping of folate deficiency (from $24 \%$ to $<1 \%$, according to the measurement of serum folate) [32, 33]. The perception that folate deficiency is quite disregarded in Europe emerges from the guidelines retrieved by the CADTH review: out of nine, only two have been developed in Europe, both by the European Federation of Neurological Societies [34, 35]. Some speculations on a remarkable prevalence of folate deficiency may be gathered from national surveys reporting on the nutritional behaviour of the populations in European countries, although the direct measurement of serum folate has been performed only in $\sim 40 \%$ of these studies $[26,28,30]$. Accordingly, it has been shown that in the Netherlands, Norway, Sweden, and Greece, the mean $( \pm$ SD) serum folate concentrations $[3.4( \pm 0.3) \mu \mathrm{g} / \mathrm{L}]$ reflects a poor food-based folate intake, which could also be dependent on the way food manufacturers supplement their grain products [26]. A moderate intake [estimated by a mean $( \pm S D)$ serum folate of $5.6( \pm 0.8) \mu \mathrm{g} / \mathrm{L}]$ has been reported for Finland, Ireland, Czech, Italy, and Portugal, whereas favorable folate concentrations in serum $(7.3 \pm 0.6$ $\mu \mathrm{g} / \mathrm{L}$ ) have been detected in UK, Germany, and Spain [28].

In Italy, there are few updated evaluations on serum folate concentrations in the general population under healthy conditions. The first study, performed on blood donors, dates back to 2000 [36]. The mean folate concentration for all case series $(\mathrm{n}=201)$ was $\sim 5.0 \mu \mathrm{g} / \mathrm{L}$, with no sex-dependent differences. The rate of subjects below the adopted lower reference limit [i.e. $3.0 \mu \mathrm{g} / \mathrm{L}$ by Abbott Diagnostics microparticle enzyme immunoassay (MEIA)] was 9.9\%, with no gender dependence [36]. More recently, Zappacosta et al. [37] evaluated serum folate concentrations in blood donors accrued in the middle-southern Italy. On a case series of 240 subjects, the overall mean folate concentration (Abbott MEIA) was $4.8 \mu \mathrm{g} / \mathrm{L}$, with concentrations being slightly higher in women. From this study, we cannot estimate the percentage of subjects with folate deficiency, but, by defining adequate serum folate concentrations as $>6.6 \mu \mathrm{g} / \mathrm{L}$, the authors observed that only $22.5 \%$ of the study participants showed an adequate folate intake. Results from multiple logistic regression showed that female gender, older age, no smoking habit, regular physical activity, and consumption of at least three portions of vegetable/fruits per day promoted higher folate concentrations [37]. Two further studies specifically focusing on the age dependence of folate concentrations in serum have reported that folate deficiency increases with age, showing in the elderly a prevalence of $\sim 5 \%$ in the $65-74$-year range and of $\sim 10 \%$ in individuals $>75$ years old, respectively [31, 38]. Sofi et al. [39] in evaluating dietary habits and lifestyle of Italian subjects, measured serum folate in 520 ostensibly healthy subjects, showing mean $( \pm \mathrm{SD})$ values of $5.4( \pm 2.6) \mu \mathrm{g} / \mathrm{L}$. Girelli et al. [29], investigating on the relationship between folate status and activity of 5,10-methylenetetrahydrofolate reductase (MHTFR) as risk factor for cardiovascular disease (CVD), reported similar concentrations in 222 CVD-free controls and found $\sim 24 \%$ of apparently healthy subjects with an inadequate folate status on the basis of their MHTFR genotype. This study addressed an additional public health problem related to folate status, not considered by CADTH but relevant for Caucasian populations: the considerable prevalence of MHTFR homozygous mutation (10\%-18\%) and the inverse association between folate concentrations in serum and both homocysteine status and CVD risk. Although the evidence on the relationship between folate status and CVD risk is mild, the correction of hyperhomocysteinemia with folic acid supplementation is widely used in the general population as well as the combined (re)testing of serum folate and plasma homocysteine for therapeutic monitoring [40].

In conclusion, in the European region, the adequacy of folate status appears to be widely variable across countries and some populations appear to be characterized by a suboptimal folate intake. Lacking robust data, we can doubt that the problem of a folate deficiency in the general population may be underestimated and neglected.

\section{Tackling the problem by a health technology assessment (HTA) approach}

As discussed above, for several European countries data on folate status in the general population are scarce and dated although public health authorities are engaging in efforts to increase overall folate intake according to the US model, in particular in women of childbearing age for the prevention of neural tube defects (NTD) [41, 42]. In a recent report, Mastroiacovo and Corchia have observed that serum folate concentrations in this women subset are comparable to those found in the US female population of the same age in the 1988-1994 period before the fortification [42]. Notably, these levels are lower than recommended by the World Health Organization (WHO) and far lower than those concentrations minimizing the risk for NTD [43]. In the USA, the folate status and changes in prevalence of folate deficiency occurring after fortification have been strictly monitored: contemporary to a 54.5\% increase in folate concentrations, a decrease of NTD cases from 10.7 to 7.0/10,000 cases/year after fortification has been recorded [43]. A cost-benefit analysis has clearly shown that health and economic gains associated 
to serum folate increase after folic acid fortification far outweighed the losses [44]. Indeed, the consequent enhanced prevention of myocardial infarction, colorectal cancer, NTD, and vitamin $\mathrm{B}_{12}$ deficiency masking resulted in a direct positive impact on health outcomes, such as annual burden of disease, quality-adjusted life years, and costs [44]. Tackling the folate issue by involving key stakeholders in healthcare policy and decision-making such as health management and clinical professions, industry, patient organizations, third-party NTD, and government has been therefore successful [45].

Firmly rooted in research and in the scientific method, HTA aims to support policy makers in making evidenceinformed decisions on the application of scientific knowledge in healthcare and prevention [46]. HTA covers a broad range of relevant expertise comprising diagnostic and treatment methods, medical equipment, pharmaceuticals, rehabilitation and prevention methods, and the organizational and supportive systems within which healthcare is provided [47]. In agreement with the HTA approach, the US National Health and Nutrition Examination Survey (NHANES) program has involved a multidisciplinary panel of 23 experts in folate and vitamin assessment, epidemiology, clinical laboratory science, and biostatistics. The roundtable also had 10 scientists from governmental agencies that conducted and funded folate biomarker measurements in NHANES surveys and developed relevant reference methods and materials [45]. A part from documenting a sharp increase then followed by a slight decrease during the 12-year post-fortification period, the roundtable reported on the quality of folaterelated measurement procedures, on the quality of reference procedures and reference materials available or under development, as well as provided public health considerations for the choice of which folate-related biomarkers to measure in the population [45]. Accordingly, US Health Advisory Committees with respect to European counterparts have paid greater attention to the measurement of the actual folate status more than to folate intake in the general population, monitoring folate concentrations in the US population from pre- (1988-1994) to post-fortification (1999-2010) period and estimating or predicting the consequent improvement of health outcomes. Notably, they also focused on the assays available for folate testing and on the analytical issues.

\section{Choice of the test for assessing folate status}

The available literature is confusing in defining which test is more appropriate to assess the adequacy of folate intake and status. Even if the measurement of serum folate is currently accepted as the test of choice for the clinical assessment of folate status/deficiency, some authors have proposed to replace this determination with plasma homocysteine or judged more reliable the measurement of folate in red blood cells (RBC) [28]. Although its request has steeply risen because of the relationship with CVD and of a possible correction of its values with synthetic folic acid, plasma homocysteine should be considered as a non-specific functional indicator of folate status [26]. On the other hand, the selection of the sample (serum or RBC) where measuring folate may depend on the features of the population in relation to the exposure to folic acid fortification or supplementation (see below) [48].

Before clarifying the analytical issues related to folate determination in serum and $\mathrm{RBC}$, we should retrieve information on the various vitamers constituting the whole of total folate and their detectability by the available assays [45]. The predominant form of the vitamin naturally found in foods is the tetrahydrofolic (THF) polyglutamate, whereas folic acid is the form used in food fortification/enrichment and dietary supplement. The biologically active THF acid is involved in the synthesis of purines, deoxythymidine, and some amino acids. The main circulating and stable folate form is the 5-methyltetrahydrofolate (5MeTHF), whereas RBCs predominately contain long-chain polyglutamates of 5MeTHF. According to isotope dilution-liquid chromatography-tandem mass spectrometry (ID-LC-MS/MS) studies, 5MeTHF constitutes from $82 \%$ to $93 \%$ of the total folate found in native serum from healthy individuals [49-51]. Additional forms may be pteroylglutamic acid (PGA), 5-formyltetrahydrofolic acid (5FoTHF), THF, various reduced forms, UMFA, and, possibly, an intermediate product, the 4- $\alpha$-hydroxy-5MeTHF (hmTHF) [49-51]. The concentration of each form depends on factors such as dietary supplementation and food fortification [52]. Populations exposed to folic acid fortification and known to have a historical prevalence of folic acid supplementation are characterized by far higher median concentrations of 5MeTHF $(\sim 17.0 \mu \mathrm{g} / \mathrm{L})$ and UMFA $(\sim 0.4 \mu \mathrm{g} / \mathrm{L})$ when compared to subjects from countries with no fortification (7.0 and $0.10 \mu \mathrm{g} / \mathrm{L}$, respectively) [50, 53]. In addition, for RBC folate, the MTHFR C677T polymorphism affects folate vitamers distribution and thus the results strictly depend on the genotype [54, 55].

Although there is an increasing interest in detecting and quantifying serum folate forms by ID-LC-MS/MS, in particular to evaluate the effects of fortification, currently only information derived from the measurement of total folate can be used for the clinical assessment of folate status. Thus, considering the wide heterogeneity of 
forms present in individual biological samples, it is relevant to know what vitamers may be recognized by the marketed assays and enter in the estimate of "total folate". The laboratory measurement of folate is complicated because not all forms are characterized by biological activity and various inactive degradation products may interfere.

The microbiological assays exclusively enabled the evaluation of biologically active folate species, but, given the poor performance, they were replaced first in NHANES surveys and later in clinical laboratories by competitive protein-binding (CPB) measurement procedures, assuring higher repeatability and reproducibility, but with some problems of bias [45]. Using the National Institute of Standards and Technology (NIST) standard reference material (SRM) 1955, the CPB assay by Bio-Rad resulted to underestimate total folate concentrations of 2.6 and $5.8 \mu \mathrm{g} / \mathrm{L}$ by $25 \%$ and $40 \%$, respectively, when compared to ID-LC-MS/MS assigned values [56]. The use of National Institute for Biological Standards and Control (NIBSC) 03/178 International Standard revealed an underestimation of $\sim 10 \%$ for CPB Bio-Rad serum folate results at an assigned total folate concentration of $5.3 \mu \mathrm{g} / \mathrm{L}$ [57]. In general, for the Bio-Rad assay it have been reported an under recovery of 5MeTHF and a proper folic acid recovery, whereas the estimated recovery of other minor folate species was significantly lower or higher than expected [45].

With the further development of CPB assays on different automated platforms and the availability of External Quality Assessment (EQA) data, it became definitively evident that various assays bind different folate species in the sample with different affinities. The currently available CPB assays are built on the use of highly specific folate-binding proteins (FBP) extracting from the sample preferentially $5 \mathrm{MeTHF}$ and other vitamers such as folic acid and 5FoTHF [58]. The recovery may, however, vary according to total folate concentrations present in the sample: for instance, the Roche Diagnostics Folate III assay, developed according to what ID-LC-MS/MS detects [59], measures an average composition of 93.3\% 5MeTHF, $2.3 \%$ folic acid, and 4.4\% 5FoTHF in serum samples with total folate $<22 \mu \mathrm{g} / \mathrm{L}$, and an average composition of $81.7 \%$ 5MeTHF, $15.7 \%$ folic acid and 2.5\% 5FoTH for total folate concentrations $>22 \mu \mathrm{g} / \mathrm{L}$ (A. Ruschel-Mitscherlich, personal communication). CPB assays have also a tendency to over recover PGA and this suggests an increased bias in total folate measurements for samples containing increased concentrations of PGA. Therefore, CPB assays would be more appropriate for the measurement of sera with total folate $<22 \mu \mathrm{g} / \mathrm{L}$, that is to say when used to test populations not receiving staple foods fortified with PGA
[60]. Finally, the affinity of various CPB assays may be further affected by slight deviations from the optimal $\mathrm{pH}$ of 9.3, particularly at the binding phase [61, 62]. Considering all the described issues, it should not be surprising that EQA results for serum folate exhibit a poor intermethod agreement, particularly at clinically significant low concentrations of the analyte [63-65].

The selected calibration regimens may undoubtedly contribute to the lack of method comparability. As anticipated above, two reference materials for folate became available in the last years for implementing traceability of the commercial assays. The NIST SRM 1955 has certified values for $5 \mathrm{MeTHF}$, reference values for folic acid and information values for total folate and 5FoTHF. Out of three level materials, only the level 2 material (with total folate concentration of $5.8 \mu \mathrm{g} / \mathrm{L}$ ) provides, however, a reliable quality to be used as calibration material being an unaltered frozen human serum, whereas commutability issues may arise with the use of levels 1 (diluted material) and 3 (fortified material) [56]. Importantly, this material is currently out of stock and information on a new lot release is not available. Being lyophilized, commutability could also be an issue for the other reference material, the NIBSC 03/178 International Standard (available since 2007) [57]. Its total folate concentration, determined using ID-LC-MS/MS, is $5.33 \mu \mathrm{g} / \mathrm{L}$, made up of $4.3 \mu \mathrm{g} / \mathrm{L}$ 5MeTHF, $0.7 \mu \mathrm{g} / \mathrm{L}$ 5FoTHF, and $0.33 \mu \mathrm{g} / \mathrm{L}$ folic acid [57].

The NHANES experts agree on the alternative use of serum and $\mathrm{RBC}$ folate measures to monitor folate concentrations in the US population, warning that the first one reflects recent intakes and may be more appropriate for the clinical detection of deficiency [45]. On the other hand, they suggest that in fortified countries the determination of $\mathrm{RBC}$ folate is preferable, being a sensitive and long-term (4 months on average) indicator of folate status and stores [45]. Both serum and RBC assays are more responsive to interventions with folic acid in supplements and fortified foods than to natural food folates (THF polyglutamate), but the increase of serum vs. RBC folate concentrations consequent to folic acid fortification in the US was far higher $(+119 \%-161 \%$ vs. $+44 \%-64 \%$, respectively) $[66,67]$. In addition, the RBC folate concentrations did not show the expected plateau effect if tissue saturation occurs at higher intakes [68]. On the other hand, RBC folate concentrations fall with vitamin $B_{12}$ deficiency, which makes them useful in the evaluation of folate effects on vitamin $B_{12}$ deficient subjects.

A mandatory prerequisite to obtain reliable folate results is to prevent the loss of 5MeTHF by promptly processing samples according to their stability $(2 \mathrm{~h}$ at room temperature, $48 \mathrm{~h}$ at $2-8^{\circ} \mathrm{C}$ or freezing at $-70^{\circ} \mathrm{C}$ for longer 
period) [69]. For RBC folate, the in vitro conversion of $5 \mathrm{MeTHF}$ polyglutamates to monoglutamates may further complicate the pre-analytical phase [26]. Furthermore, for serum folate determination fasting is required as well as the rejection of hemolyzed samples [free hemoglobin $(\mathrm{Hb}) \geq 0.25 \mathrm{~g} / \mathrm{L}]$.

A final important aspect is the definition of decision level for serum folate indicating negative folate balance/ folate deficiency in the evaluated population. Over the past three decades, the threshold has been widely reviewed, passing from 3.0 to $4.4 \mu \mathrm{g} / \mathrm{L}$, when the definition accounted for the relationship with a metabolic indicator (i.e. increase of plasma homocysteine). Although the implementation of folate cut-offs had a pivotal role in promoting public health interventions gaged on NHANES surveys [70-72], the use of decision values could be inconsistent and the individual chronic folate deficiency may be stochastically found by multiple serial testing. According to the estimation of biological variation of folate in serum, the far lower within-person variation with respect to the inter-individual variation implies a low index of individuality (i.e. ratio of within- to between-subject variances), i.e. 0.44 [73]. Under this condition, an isolated dichotomized interpretation of folate results, resorting to a decision limit for deficiency, can be misleading and the longitudinal monitoring of serial folate changes be more effective in classifying individuals with relation to their vitamin status. This approach is also supported by the number of samples needed to theoretically establish an individual's homeostatic set point. According to the current statistical approach [74], the number of specimens that should be collected to ensure that the mean marker result is within $\pm 10 \%$ of the individual's homeostatic set point can be obtained according to the following statistics: $1.96^{2}$ (analytical $\mathrm{CV}^{2}+$ within-subject biological $\left.\mathrm{CV}^{2}\right) / 100$. Using an average analytical CV of $4.0 \%$ and an average intra-individual CV of $21.5 \%$ [73], for folate, it can be estimated that each subject should theoretically undergo up to 18 marker measurements to achieve a sufficiently accurate estimate of the folate individual's homeostatic set point, which is clearly unfeasible.

\section{Status of folate testing in Italy}

\section{Inpatients and outpatients}

Aiming to characterize the prevalence of folate deficiency in the served patient population of our academic metropolitan hospital, we retrieved a 1-year (April 2015-April
2016) case series of consecutive serum folate results from our laboratory information system. Out of 4225 folate values obtained by using Roche Diagnostics Folate III assay (code 04476433190) performed on the Modular EVO platform, $\sim 11.0 \%$ were $>20 \mu \mathrm{g} / \mathrm{L}$, the remaining cases exhibiting a median (25th-75th percentile) concentration of $6.4(4.8-9.0) \mu \mathrm{g} / \mathrm{L}$. By selecting results below the lower reference limit recommended by the manufacturer of our folate assay $(4.6 \mu \mathrm{g} / \mathrm{L}), 861(20.4 \%)$ results characterized subjects as at risk for folate deficiency. In this subset of individuals, the median (25th-75th percentile) folate concentration was $3.8(3.2-4.2) \mu \mathrm{g} / \mathrm{L}$. The frequency distributions of serum folate concentrations in outpatients $[\mathrm{n}=2318 ; 16.8 \%<4.6 \mu \mathrm{g} / \mathrm{L}$; median $(25 \mathrm{th}-75$ th percentile) 6.8 (5.1-9.4) $\mu \mathrm{g} / \mathrm{L}$, excluding 285 (12.3\%) subjects $>20 \mu \mathrm{g} / \mathrm{L}]$ and inpatients $[\mathrm{n}=1907 ; 24.8 \%<4.6 \mu \mathrm{g} / \mathrm{L}$; median (25th-75th percentile) 6.0 (4.4-8.4) $\mu \mathrm{g} / \mathrm{L}$, excluding $181(9.4 \%)$ subjects $>20 \mu \mathrm{g} / \mathrm{L}]$ are reported in Figure 1.

By analyzing folate ordering, we observed that, with the exception of patients carrying myelogenous leukemia (adding up 9.8\% of orders), requests were not preferentially attributable to some specific wards or to specific sets of outpatients. In particular, $8.9 \%$ and $10.2 \%$ of requests concerned patients admitted to Departments of Internal Medicine and Infectious Disease, while the number of requests coming from other divisions was lower [Neurology and Stroke Unit (7.6\%), Nephrology and Dialysis (4.6\%), and Gastroenterology (3.5\%)]. More than half of the total results below the lower reference limit were partitioned among the Department of Internal Medicine (25.3\%), the Department of Infectious Disease (15.4\%), and general outpatients (18.1\%). Neurology and Stroke Unit (8.7\%), Nursing Home Care (7.1\%), Outpatients carrying Myelogenous Leukemia (5.7\%), Nephrology and Dialysis (4.1\%), Gastroenterology (3.7\%), Reumatology (2.1\%), and Oncology (1.6\%) showed a lower prevalence of serum folate reduction.

Considering folate retesting, we found 732 results from 337 retested patients (62.4\% outpatients). Each patient had a mean (SD) of 2.2 (0.4) requests/year, in $14.2 \%$ of patients, the folate tests being $\geq 3$. The average (SD) time interval of retesting was 3.4 (2.5) months between the first two requests and 3.1 (2.0) months between the second and the third one. Figure 2 displays the frequency distribution of absolute and percentage changes between the first two serial measurements of serum folate in retested subjects. Accounting for an average intra-individual CV of $21.5 \%$ [73] and the analytical CV of the assay, one can derive the reference change value (RCV) for serum folate. The RCV is defined as the change needed between two serial results from the same individual to be significantly 


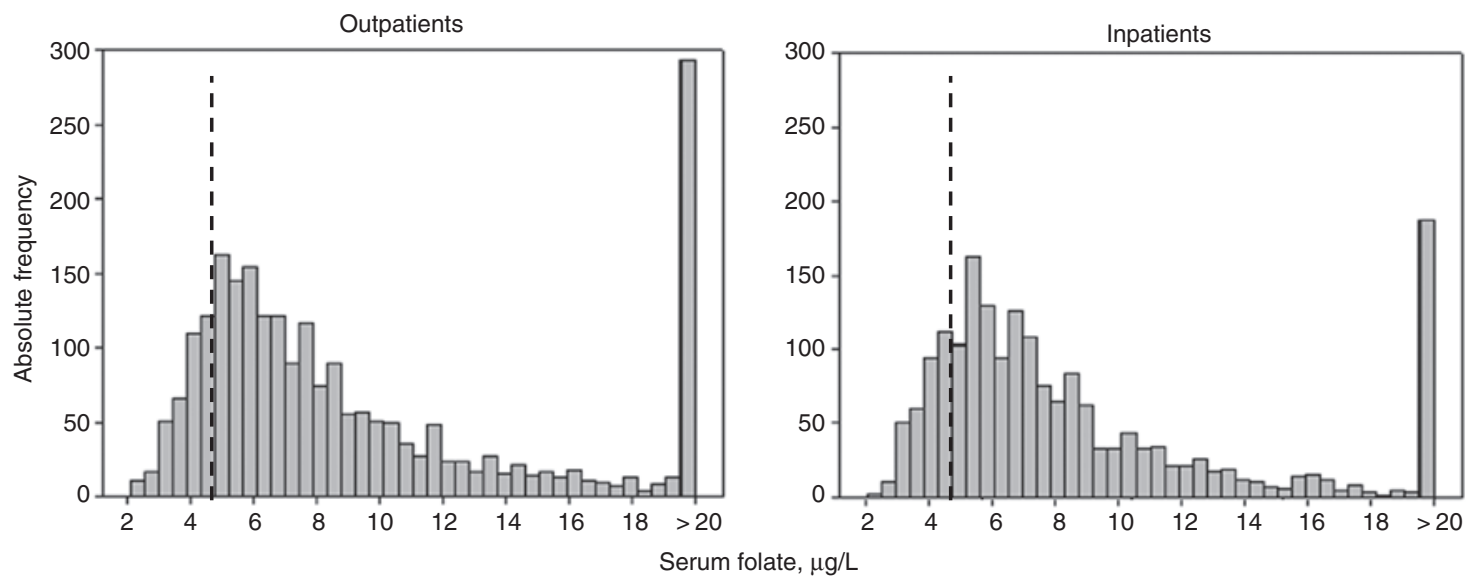

Figure 1: Frequency distributions of serum folate results in outpatients $(n=2318)$ and inpatients $(n=1907)$ retrieved from 1-year consecutive case series in the population served by the authors' laboratory.

Vertical dashed lines indicate the lower reference limit $(4.6 \mu \mathrm{g} / \mathrm{L})$ recommended by the manufacturer of folate assay (Roche Diagnostics Folate III, code 04476433190).
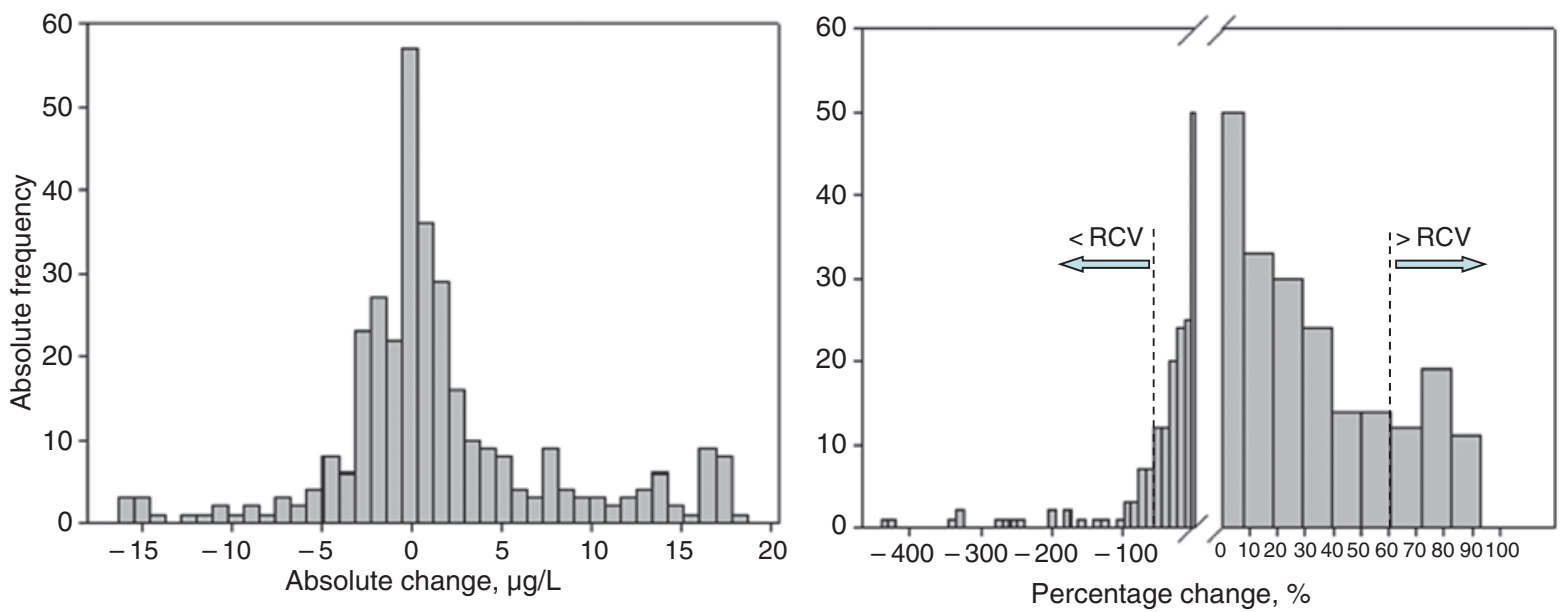

Figure 2: Frequency distribution of absolute and percentage changes between the first two serial measurements of serum folate in retested subjects $(n=337)$ from the surveyed population.

$\mathrm{RCV}$, reference change value.

different, beyond the measurement error and the biological variability of the analyte [74]. In particular, at the average analytical CV for our assay of $4.0 \%$ (data from 2015 fiscal year internal quality control), the derived RCV for serum folate is $60.6 \%$. By applying it to our population, we can identify a subgroups of 43 subjects (12.8\% of retested patients) with a positive change $>60.6 \%$ between the two serial tests, likely related to a recently started folic acid supplementation, and another group of 32 individuals $(10.4 \%)$ with a decrease in serum folate $>$ RCV, in whom an actual folate deficit was conceivable (Figure 2). Interestingly, only 12 subjects in the latter group had the second value $<4.6 \mu \mathrm{g} / \mathrm{L}$, suggesting a possible underestimation of vitamin deficiency if the evaluation is resorting to a fixed cut-off. Furthermore, 14 individuals from this subgroup showed a baseline value $>14 \mu \mathrm{g} / \mathrm{L}$ indicating a recently interrupted supplementation. It is noteworthy that folate body stores generally represent a 2-3 months supply, and after stopping supplementation, folate deficiency may suddenly occur for an inadequate intake or increased requirement for the vitamin [75]. The remaining 262 retested subjects displaying a change $<60.6 \%$ between two measurements (i.e. a stable trend of folate values) could be in turn divided into three subsets, the first with folate values stably $\geq 14 \mu \mathrm{g} / \mathrm{L}$, indicating an ongoing supplementation, the second with baseline values inside the reference interval and the third with baseline folate concentrations $<4.6 \mu \mathrm{g} / \mathrm{L}$. In the first and the third subsets, 




Figure 3: Typical patterns of serum folate change in retested subjects. The average (SD) time of retesting was 3.4 (2.5) months. (A) Subject with a positive change higher than the reference change value (RCV) (60.6\%), likely related to a recently started folic acid supplementation; (B) subject with a decrease in serum folate $>R C V$, in whom an actual folate deficit is conceivable; (C) subject with a decrease in serum folate $>$ RCV and a baseline value $>14 \mu \mathrm{g} / \mathrm{L}$, indicating a recently interrupted supplementation; (D) subject with folate values stably $\geq 14 \mu \mathrm{g} / \mathrm{L}$, indicating an ongoing supplementation; (E) subject with baseline value inside the reference interval and change lower than RCV, indicating a unchanged lifestyle; (F) subject with folate concentrations lower than the lower reference limit, indicating a possible folate deficiency.

the retesting was not justified. Figure 3 displays typical patterns of folate change found in retested subjects.

\section{Healthy population}

We also retrieved data from a continuous case series of 538 blood donors [men, 58.4\%; median (25th-75th percentile) age, 36 (25-45) years, $11.3 \%$ non-Italian] routinely tested for serum folate (Roche Folate III assay, code 04476433190). Among these subjects, three had concentrations $>20$ $\mu \mathrm{g} / \mathrm{L}$, and the remaining 535 , a median concentration of $6.0 \mu \mathrm{g} / \mathrm{L}$, with 2.5th and 97.5th percentile limits at 3.3 and $13.9 \mu \mathrm{g} / \mathrm{L}$, respectively. Figure 4 reports the frequency distribution. There was no correlation between serum folate and blood $\mathrm{Hb}$ concentrations and between folate and the mean corpuscular volume of erythrocytes in these subjects. Interestingly, 100 (18.6\%) of these apparently healthy individuals were below the assay manufacturer's declared lower reference limit $(4.6 \mu \mathrm{g} / \mathrm{L})$ that was apparently too high for our population. On the other hand, by defining the adequate status of folate according to Dhonukshe-Rutten et al. [28] as serum concentrations $>6.6$ $\mu \mathrm{g} / \mathrm{L}$, we observed that only $40.7 \%$ of subjects seemed to have an adequate folate intake from diet. A significant

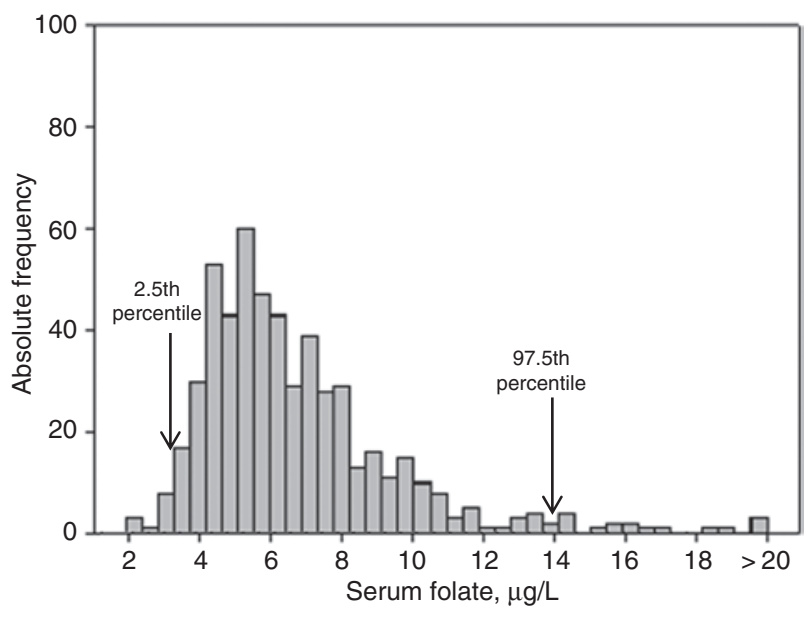

Figure 4: Frequency distribution of folate concentrations in serum of 538 healthy blood donors.

Arrows indicate the 2.5 th $(3.3 \mu \mathrm{g} / \mathrm{L})$ and the 97.5 th $(13.9 \mu \mathrm{g} / \mathrm{L})$ percentile of value distribution.

increase $(\mathrm{p}<0.01)$ of folate concentrations in serum was shown with age increase, in female gender, and in nonItalian individuals.

\section{Appropriateness of test request}

In agreement with previous reporting claiming an overuse/misuse of serum folate testing [1, 4], we confirmed an excess of test requests in our institution quite equally distributed between different population subsets and often consistent with screening purposes. Furthermore, according to our data, the proportion of subjects undergoing folate testing during or just after vitamin supplementation seems to be quite relevant, even if testing folate in these patients is probably useless for some consolidated reasons:

(a) except for patients with pernicious anemia, an intake of synthetic folic acid is unlikely to be associated with adverse events [21];

(b) there are no data assuring that the available assays can reliably detect serum folate absolute concentrations related to the maximum tolerable intake level of folic acid (i.e. $5 \mathrm{mg} /$ day in the general population or $1 \mathrm{mg} /$ day in the elderly and in patients with pernicious anemia) [21];

(c) serum folate concentrations may rapidly fall down after discontinuing the assumption [76].

The data by Hao et al. [76] support the doubts on the effectiveness of monitoring folic acid supplementation. These authors showed that in healthy women, the 
supplementation with $0.4 \mathrm{mg} /$ day corresponds to circulating folate concentrations of approximately $16 \mu \mathrm{g} / \mathrm{L}$, measured 3 months after starting ('plateau level'). No further increase is recorded at 6 months, whereas a rapid decrease ( $-55 \%$ in average) occurs 3 months after discontinuing supplementation. For higher folic acid doses (i.e. $4 \mathrm{mg} /$ day, which is close to the tolerable upper intake level), serum folate concentrations amounted to $24 \mu \mathrm{g} / \mathrm{L}$ after the first 3 months and showed a far sudden decrease $(-66 \%)$ after cessation [76].

In agreement with these experimental data, we can argue that there is no suitable cost-effectiveness in monitoring the vitamin supplementation by folate testing. Furthermore, considering that the folic acid intake is no harmful in the general population and only patients with pernicious anemia may be potentially affected if supplemented with $>1 \mathrm{mg} /$ day (corresponding to a serum plateau level of $\sim 20 \mu \mathrm{g} / \mathrm{L}$ ), the dilution of samples with folate concentrations $>20 \mu \mathrm{g} / \mathrm{L}$ (i.e. the upper calibration limit for several assays), once the test is executed, to provide definite concentrations within $40 \mu \mathrm{g} / \mathrm{L}$ (corresponding to the highest folic acid intake) is also not cost-effective. On the other hand, it is proved that, by discontinuing intake, folate retesting is useless to evaluate the actual correction of the deficit [77].

In summary, the serum folate test is inappropriately ordered when

(a) there is no specific risk condition/suspicion for folate deficiency/inadequate status (Table 1);

(b) the subject is undergoing or has recently undergone folic acid supplementation;

(c) retesting at 3-6 months to evaluate the actual correction of the deficit after intake discontinuation.

By applying these recommendations on the current folate testing strategy applied in our institution, we can estimate a $\sim 50 \%$ saving in laboratory costs.

\section{Estimating folate deficiency and need to predict the effect of assay recalibration}

In the general population, serum folate testing is frequently used to screen for vitamin deficiency. In our experience, $\sim 94 \%$ of requests are indeed associated to those for vitamin $B_{12}$ testing. According to our data, the prevalence of subjects exhibiting folate concentrations below the lower reference limit is actually remarkable in any evaluated setting (inpatients, $\sim 25 \%$; outpatients, $\sim 17 \%$; healthy subjects, $18.6 \%$ ), always quite far from estimates in fortified countries [6]. How this frequency is directly connected with the prevalence of folate deficiency and how much it is conversely dependent from the correctness of cut-off establishment and its usefulness and from accuracy of folate assays is, however, unknown.

It has long been known that the actual prevalence of folate deficiency in the population may significantly shift with the reformulation of assays [78]. This is troublesome when monitoring over time trends in folate concentration distributions to promote public health intervention and policies on the population $[26,63,64]$. To improve harmonization of assays, some commercial folate methods have recently undergone recalibration to the NIBSC 03/178 International Standard in order to fulfil the European Union Directive on in vitro diagnostic medical devices that asks diagnostic manufacturers to ensure traceability of their analytical systems to recognized higher-order references [79]. However, tracing back the calibration of commercial assays to a new reference material can modify results and actually alter their relation to existing reference intervals and decision limits, invalidating the clinical decisionmaking criteria currently used [80-82]. In fact, we have recently experienced this problem when Roche Diagnostics has replaced the Folate III assay code 04476433190 (which was home-made calibrated) by the Folate III assay code 07559992190 (traceable to NIBSC 03/178 material). After the kit replacement, we immediately recorded a significant change in the average folate value measured on a fresh-frozen serum pool used daily to check the longterm assay imprecision, with a mean underestimation of $28.8 \%$ of total folate when measured by the new version of the assay (6.6 vs. $4.7 \mu \mathrm{g} / \mathrm{L}$, respectively). We confirmed the effect of assay recalibration in providing lower folate results by a preliminary comparison study on 15 clinical samples, aliquoted and stored at $-80{ }^{\circ} \mathrm{C}$, measured by each assay. Comparing the previous with the new assay, the mean $( \pm \mathrm{SD})$ folate concentrations resulted $6.6( \pm 0.5)$ vs. $4.7( \pm 0.4) \mu \mathrm{g} / \mathrm{L}$, respectively (average bias, $-28.8 \%$ ). A stronger proof was finally derived from the regional EQA program where, by cumulating interlaboratory data generated by participants using the Roche assay, a dichotomous distribution of total folate results became evident. After partitioning data for assay code, the obtained mean $( \pm \mathrm{SD})$ for laboratories using code 04476433190 assay $(\mathrm{n}=6)$ was $4.0( \pm 0.4) \mu \mathrm{g} / \mathrm{L}$ vs. $2.0( \pm 0.5) \mu \mathrm{g} / \mathrm{L}$ for code 07559992190 laboratories $(\mathrm{n}=30)$ [data from EQA exercise no. 4/2016]. Thus, we can speculate that at a folate concentration around the lower reference limit of the old assay, a positive bias of $50 \%$ vs. the new assay can be observed. 
Given this large variation in folate results, it is very relevant to predict the impact due to the introduction of the recalibrated assay on the prevalence of folate deficiency with respect to the previous generation assay. In the modified package insert, the assay manufacturer is recommending a new lower reference limit $(3.9 \mu \mathrm{g} / \mathrm{L})$ for the interpretation of serum folate results in European populations. Taking into account the $\sim 50 \%$ between-assay difference experimentally found at this concentration level, the shift from $4.6 \mu \mathrm{g} / \mathrm{L}$ (old calibration) to $3.9 \mu \mathrm{g} / \mathrm{L}$ (new calibration assay) appears, however, to be inconsistent. Consequently, a misleading overestimate of the prevalence of folate deficiency is expected if the recalibrated Roche assay will be used together the manufacturer's newly recommended lower reference limit. New experimental data from healthy blood donors (similar to those presented in Figure 4 for the former assay) have, therefore, to be quickly obtained with the recalibrated assay in order to accurately define the reference distribution in the proper population and derive decisional strategies for folic acid supplementation. This might also require the (re)formulation of safe and effective health policies that are patient-focused and seek to achieve the best outcome.

\section{Concluding remarks}

Today, the evaluation of folate status and intake still represents an important aspect that healthcare systems of several European countries have to deal with. Several surveys have reported that the folate intake and status in most European countries are suboptimal to ensure physiologic growth and fetal development and maintenance of optimal health [28]. Considering the poor stability and incomplete bioavailability of natural food folates when compared to the synthetic form, approaches to optimize vitamin intake and improve health population outcomes, in particular focusing on the NTD risk reduction, have to be considered [41, 42, 72]. Some authors agree with the introduction of mandatory fortification following the US and Canada policies, while others boost for the supplementation with folic acid capsules of groups at risk (i.e. elderly and women of childbearing age) [83, 84]. In general, in policy decisions, Europe shows a greater caution than North America region, dictated by the safety issues of folic acid supplementation/fortification [32, 85]. Concerns have been raised about the potential adverse effects of high circulating concentrations of folic acid and of traces of UMFA, the latter not reliably detectable by clinical assays [86-88]. Finally, the information derived from the recent medical literature showing no decrease in the incidence of NTD in Europe [89] should be considered in promoting or not supplementation strategies.

The ability to develop regional or national consensus strategies on populations at risk and to promote evidence-based health policy-making are contingent on having reliable data and this cannot disregard the knowledge of biomarkers of folate status and of related assays [25]. Reviews by multidisciplinary panel of authoritative experts have focused on the pre-analytical, analytical, and post-analytical issues related to the biomarkers of folate status, clarifying that the choice of the method (serum or $\mathrm{RBC}$ folate) depends on the features of the investigated population (prevalence of deficiency, spread of fortified staple food) and on the outcome (assessment of the individual folate status/risk for deficiency or characterization of the population intake/status) $[6,26,28,90]$. For surveys on the general population, the measurement of serum folate may not be a reliable method, but it becomes the test of choice for the clinical use and the assessment of individual deficiency [26]. Fulfilling recommendations on the pre-analytical management of samples is mandatory to obtain reliable results, but it is their interpretation that is central for identifying individual risk for folate deficiency. In addition to the limited usefulness of a cut-off value (i.e. the lower reference limit) due to the wide inter-individual biological variability of folate, we can doubt on the reliability of the reference intervals reported by assay manufacturers and recommended for European populations $[28,73]$. As across European countries, the voluntary and liberal fortification policies are greatly heterogeneous, the estimation of reference intervals is likely to be conditioned by the possible inclusion in the reference group of subjects consuming fortified staple foodstuffs [28, 37]. Furthermore, results obtained by investigating and comparing folate intake across populations have suggested shifting the outcome from detecting folate deficiency to assessing folate status at the individual level. As reported by Bailey et al. [91], meeting a criterion for assessing individual folate deficiency (or its prevalence in a population) is not synonymous of optimal folate status also in the "not deficient" portion of the population [91]. In several settings, although an out-and-out folate deficiency may be rare, a suboptimal folate status impairing health conditions may be more common and, for this reason, the test ordering should be appropriately addressed.

A cost-effective use of folate testing in the clinical setting implies the knowledge of (a) what biomarker order, (b) what population investigate, and (c) when or if retest. All main documents agree on the use of serum folate testing without adding homocysteine test when the 
outcome is to evaluate the individual risk of folate deficiency/status $[6,26]$. In countries undergoing mandatory fortification, the population exhibits a distribution of circulating folate vitamers different from European countries and the prevalence of deficiency in the general population is far lower [52]. Accordingly, in fortified populations the test request should be restricted to some groups at risk, but not recommended in both inpatients and outpatients [5]. In European countries, particularly in those not adopting national fortification policies, these recommendations should be cautionary considered, since there is a sounded evidence of a suboptimal folate intake in the general population. Our local data further show a considerable prevalence of risk for deficiency in all tested populations (outpatients, inpatients, and blood donors) and suggest that in all these subsets folate testing may be ordered according to the individual risk and to the suspect for an inadequate intake, possibly requiring correction with folic acid supplementation or simply a change in dietary habits. We should remind that several European National Institutes of Health are working to promote the implementation of healthcare policies to enhance the general availability of fortified foods with the final aim to prevent in the population the increase of clinical conditions and genetic defects linked to an impaired folate status [42, 92-94]. Starting from 2005, the National Health System in Italy enables healthcare providers to prescribe folic acid supplements without any charge to all women of childbearing age (the cost to the National Health System of a box containing 28 pills of $400 \mu \mathrm{g}$ folic acid is $\sim 2 €$ ) [41]. Facing on data on the prevalence of folate deficiency, the need for a possible extension of this policy to other groups at risk (e.g. the elderly) may be considered. Finally, we should remind that it is useless to measure and monitor by retesting serum folate in individuals undergoing supplementation, since this cannot warrant a long-term supply (>3 months) (examples C and D in Figure 3) [75, 76]. Furthermore, repeating folate measurement is also useless in individuals with strongly suspected folate deficiency (example F in Figure 3) [77].

In conclusion, with respect to fortified countries, in European populations, there is evidence on the need and relevance to perform serum folate testing without specific restrictions. According to the data analysis, it is, however, mandatory to boost for more appropriate requests to curb the excess of costs linked to the spreading of folate testing. We should emphasize that the effectiveness of the test is maximized when oriented to subjects suggestive or at risk for deficiency and low or absent when used as tool for screening or serial monitoring of vitamin intake or supplementation. In the latter case, to prevent retesting, a computer-based-limiting management strategy may be considered [95]. Finally, we should be aware that the recent recalibration of several commercial assays in view of harmonization policies is likely significantly shifting results and, if not correctly managed, potentially affecting the detection of folate deficiency in individuals at risk.

Acknowledgments: The authors are grateful to Mario Cassani (Centro di Riferimento Regionale per la Qualità dei Servizi di Medicina di Laboratorio, Regione Lombardia) for providing information useful for interpreting EQA results and to Carmelo Silanos (Ospedale 'Luigi Sacco', Milano) for retrieving folate data from the laboratory information system.

Author contributions: All the authors have accepted responsibility for the entire content of this submitted manuscript and approved submission.

Research funding: None declared.

Employment or leadership: None declared.

Honorarium: None declared.

Competing interests: The funding organization(s) played no role in the study design; in the collection, analysis, and interpretation of data; in the writing of the report; or in the decision to submit the report for publication.

\section{References}

1. Theisen-Toupal J, Horowitz G, Breu A. Low yield of outpatient serum folate testing: eleven years of experience. JAMA Intern Med 2014;174:1696-7.

2. Wu AH. Folate testing: time to retire your VCR. JAMA Intern Med 2014;174:1697-8.

3. Theisen-Toupal J, Horowitz GL, Breu AC. Utility, charge, and cost of inpatient and emergency department serum folate testing. J Hosp Med 2013;8:91-5.

4. Gudgeon P, Cavalcanti R. Folate testing in hospital inpatients. Am J Med 2015;128:56-9.

5. Gilfix BM. Utility of measuring serum or red blood cell folate in the era of folate fortification of flour. Clin Biochem 2014;47:533-8.

6. Canadian Agency for Drugs and Technologies in Health. Rapid response report. Summary with critical appraisal. Folate testing: A review of the diagnostic accuracy, clinical utility, cost-effectiveness and guidelines. Available at: https://www.cadth.ca/ folate-testing-review-diagnostic-accuracy-clinical-utility -costeffectiveness-and-guidelines. Accessed August 2016.

7. Sellers AR. Memorandum. Laboratory utilization: folate testing is no longer justified in folic acid fortified countries. Charlottetown (PEI): Health PEI, 2012. Available at: http://www.gov.pe.ca/photos/original/hpei_labutlztn.pdf. Accessed August 2016.

8. Wilson RD, Johnson JA, Wyatt P, Allen V, Gagnon A, Langlois S, et al. Pre-conception vitamin/folic acid supplementation 2007: the use of folic acid in combination with a multivitamin supplement for the prevention of neural tube defects and other congenital anomalies. J Obstet Gynaecol Can 2007;29:1003-26. 
9. Robinson AR, Mladenovic J. Lack of clinical utility of folate levels in the evaluation of macrocytosis or anemia. Am J Med 2001;110:88-90.

10. MacFarlane AJ, Greene-Finestone LS, Shi Y. Vitamin B-12 and homocysteine status in a folate-replete population: results from the Canadian Health Measures Survey. Am J Clin Nutr 2011;94:1079-87.

11. Latif T, Hsi ED, Rybicki LA, Adelstein DJ. Is there a role for folate determinations in current practice in the USA? Clin Lab Haematol 2004;26:379-83.

12. Ontario Health Technology Advisory Committee. Appropriateness Phase 1 OHTAC recommendations: Annual health exams, aspartate aminotransferase testing, chloride testing, creatine kinase testing, ferritin testing, folate testing, and vitamin B12 testing. Toronto: Health Quality Ontario; 2013. Available at: http://www. hqontario.ca/Portals/Documents/eds/recommendation-appropriateness-phase-1-130722-en.pdf. Accessed August 2016.

13. Vinker S, Krantman Shani M, Nakar S. Low clinical utility of folate determinations in primary care. Am J Manag Care 2013;19:e100-5.

14. Shrim A, Kapur B, Snyder J, Basso O, Blank D, Brown RN. Maternal predictors of RBC folate levels in an urban Canadian population. Reprod Toxicol 2015;53:127-30.

15. Pfeiffer CM, Sternberg MR, Schleicher RL, Rybak ME. Dietary supplement use and smoking are important correlates of biomarkers of water-soluble vitamin status after adjusting for sociodemographic and lifestyle variables in a representative sample of U.S. adults. J Nutr 2013;143:957S-65S.

16. Yakut M, Üstün Y, Kabaçcam G, Soykan I. Serum vitamin B12 and folate status in patients with inflammatory bowel diseases. Eur J Intern Med 2010;21:320-3.

17. Chowers Y, Sela B, Holland R, Fidder H, Simoni FB, Bar-Meir $S$. Increased levels of homocysteine in patients with Crohn's disease are related to folate levels. Am J Gastroenterol 2000;95:3498-502.

18. Ede Van AE, Laan RF, Boers GH, Haagsmaq CJ, Thomas CM, Boo $\mathrm{TM}$, et al. Homocysteine and folate status in methotrexatetreated patients with rheumatoid arthritis. Rheumatology 2002;41:658-65.

19. Mahmud N, Molloy McPartlin J, Corbally R, Whitehead AS, Scott $J M$, et al. Increased prevalence of methylenetetrahydrofolate reductase 6 677T variant in patients with inflammatory bowel disease, and its clinical implications. Gut 1999;45:389-94.

20. Singh G, Singh V, Hamdan H. Clinical utility of serum folate measurement in tertiary care patients. Argument for revising reference range for serum folate from $3.0 \mathrm{ng} / \mathrm{mL}$ to $13 \mathrm{ng} / \mathrm{mL}$. A-318 Abstract presented at American Association for Clinical Chemistry Annual Meeting, $2015 \mathrm{Jul} 26$ - 30, Atlanta (GA). Available at: https://www.aacc.org/ /media/files/annual-meeting/2015/ abstracts/aacc15_am_a307a331.pdf. Accessed August 2016.

21. Opinion of the Scientific Committee on Food on the Tolerable Upper Intake Level of Folate. Available at: http://ec.europa.eu/ $\mathrm{food} / \mathrm{fs} / \mathrm{sc} / \mathrm{scf} /$ out80e_en.pdf. Accessed August 2016.

22. Mason JB, Dickstein A, Jacques PF, Haggarty P, Selhub J, Dallal $G$, et al. A temporal association between folic acid fortification and an increase in colorectal cancer rates may be illuminating important biological principles: a hypothesis. Cancer Epidemiol Biomark Prev 2007;16:1325-9.

23. Fenech $M$. The role of folic acid and vitamin B12 in genomic stability of human cells. Mutat Res 2001;475:57-67.
24. Vollset SE, Clarke R, Lewington S, Ebbing M, Halsey J, Lonn E, et al. B-Vitamin Treatment Trialists' Collaboration. Effects of folic acid supplementation on overall and site-specific cancer incidence during the randomised trials: meta-analyses of data on 50,000 individuals. Lancet 2013;381:1029-36.

25. Burr NE, Hull MA, Subramanian V. Folic acid supplementation may reduce colorectal cancer risk in patients with inflammatory bowel disease: a systematic review and meta-analysis. J Clin Gastroenterol 2016; doi:10.1097/MCG.0000000000000498.

26. Bailey LB, Stover PJ, McNulty H, Fenech MF, Gregory JF 3rd, Mills JL, et al. Biomarkers of nutrition for development-Folate review. J Nutr 2015;145:1636S-80S.

27. Ferraro S, Panteghini M. Laboratory medicine as the science that underpins medicine: the "high-sensitivity" troponin paradigm. Clin Chem Lab Med 2015;53:653-64.

28. Dhonukshe-Rutten RA, de Vries JH, de Bree A, van der Put N, van Staveren WA, de Groot LC. Dietary intake and status of folate and vitamin B12 and their association with homocysteine and cardiovascular disease in European populations. Eur J Clin Nutr 2009;63:18-30.

29. Girelli D, Martinelli N, Pizzolo F, Friso S, Olivieri O, Stranieri C, et al. The interaction between MTHFR 677 C-->T genotype and folate status is a determinant of coronary atherosclerosis risk. J Nutr 2003;133:1281-5.

30. Czeizel AE, Dudás I, Vereczkey A, Bánhidy F. Folate deficiency and folic acid supplementation: the prevention of neural-tube defects and congenital heart defects. Nutrients 2013;5:4760-75.

31. Gillette Guyonnet G, Van Kan G, Andrieu S, Barberger Gateau P, Berr C, Bonnefoy M, et al. IANA task force on nutrition and cognitive decline with aging. J Nutr Health Aging 2007;11:132-52.

32. Mills JL, Dimopoulos A. Folic acid fortification for Europe? $\mathrm{Br}$ Med J 2015;351:h6198.

33. Pfeiffer CM, Hughes JP, Lacher DA, Bailey RL, Berry RJ, Zhang M, et al. Estimation of trends in serum and RBC folate in the U.S. population from pre- to post-fortification using assay-adjusted data from the NHANES 1988-2010. J Nutr 2012;142:886-93.

34. Sorbi S, Hort J, Erkinjuntti T, Fladby T, Gainotti G, Gurvit $H$, et al. EFNS-ENS guidelines on the diagnosis and management of disorders associated with dementia. Eur J Neurol 2012;19: 1159-79.

35. Hort J, O’Brien JT, Gainotti G, Pirttila T, Popescu BO, Rektorova I, et al. EFNS guidelines for the diagnosis and management of Alzheimer's disease. Eur J Neurol 2010;17:1236-48.

36. Cafolla A, Dragoni F, Girelli G, Tosti ME, Costante A, Pastorelli $D$, et al. Folate status in Italian blood donors: relation to gender and smoking. Haematologica 2000;85:694-8.

37. Zappacosta B, Persichilli S, lacoviello L, Di Castelnuovo A, Graziano M, Gervasoni J, et al. Folate, vitamin B12 and homocysteine status in an Italian blood donor population. Nutr Metab Cardiovasc Dis 2013;23:473-80.

38. Haller J, Weggemans RM, Lammi-Keefe CJ, Ferry M. SENECA Investigators. Changes in the vitamin status of elderly Europeans: plasma vitamins A, E, B-6, B-12, folic acid and carotenoids. Eur J Clin Nutr 1996;50(Suppl 2):S32-46.

39. Sofi F, Vecchio S, Giuliani G, Martinelli F, Marcucci R, Gori AM, et al. Dietary habits, lifestyle and cardiovascular risk factors in a clinically healthy Italian population: the 'Florence' diet is not Mediterranean. Eur J Clin Nutr 2005;59:584-91.

40. Homocysteine Lowering Trialists' Collaboration. Dosedependent effects of folic acid on blood concentrations of 
homocysteine: a meta-analysis of the randomized trials. Am J Clin Nutr 2005;82:806-12.

41. Mastroiacovo P, Addis A. Folic acid: a public-health challenge. Lancet 2006;367:2057.

42. Mastroiacovo P, Corchia C. Riflessioni sulla prevenzione primaria dei difetti del tubo neurale in Italia e spunti per una raccomandazione basata sulle evidenze più recenti. Available at: www. acp.it/wp-content/uploads/Quaderni-acp-2016_231_20-23.pdf. Accessed August 2016.

43. Williams J, Mai CT, Mulinare J, Isenburg J, Flood TJ, Ethen M, et al. Updated estimates of neural tube defects prevented by mandatory folic acid fortification - United States, 1995-2011. Morb Mortal Wkly Rep 2015;64:1-5.

44. Bentley TG, Weinstein MC, Willett WC, Kuntz KM. A costeffectiveness analysis of folic acid fortification policy in the United States. Public Health Nutr 2009;12:455-67.

45. Yetley EA, Pfeiffer CM, Phinney KW, Fazili Z, Lacher DA, Bailey RL, et al. Biomarkers of folate status in NHANES: a roundtable summary. Am J Clin Nutr 2011;94:303-12S.

46. Velasco Garrido M, Kristensen FB, Palmhøj Nielsen C, Busse R. Health technology assessment and health policy-making in Europe. Current status, challenges and potential. Available at: www.euro.who.int/_data/assets/pdf_file/0003/90426/ E91922.pdf. Accessed August 2016.

47. Kristensen FB. EUnetHTA and health policy-making in Europe. Eurohealth 2006;12:36-8.

48. Pfeiffer CM, Sternberg MR, Fazili Z, Lacher DA, Zhang M, Johnson $\mathrm{CL}$, et al. Folate status and concentrations of serum folate forms in the US population: National Health and Nutrition Examination Survey 2011-2. Br J Nutr 2015;113:1965-77.

49. Fazili Z, Pfeiffer CM. Measurement of folates in serum and conventionally prepared whole blood lysates: application of an automated 96-well plate isotope-dilution tandem mass spectrometry method. Clin Chem 2004;50:2378-81.

50. Kirsch SH, Knapp JP, Herrmann W, Obeid R. Quantification of key folate forms in serum using stable-isotope dilution ultra performance liquid chromatography-tandem mass spectrometry. J Chrom B 2010;878:68-75.

51. Hannisdal R, Ueland PM, Svardal A. Liquid chromatographytandem mass spectrometry analysis of folate and folate catabolites in human serum. Clin Chem 2009;55:1147-54.

52. Kalmbach RD, Choumenkovitch SF, Troen AM, D’Agostino R, Jacques PF, Selhub J. Circulating folic acid in plasma: relation to folic acid fortification. Am J Clin Nutr 2008;88:763-8.

53. Bailey RL, Dodd KW, Gahche JJ, Dwyer JT, McDowell MA, Yetley EA. Total folate and folic acid intake from foods and dietary supplements in the United States: 2003-2006. Am J Clin Nutr 2010;91:231-7.

54. Fazili Z, Pfeiffer CM, Zhang M, Jain RB, Koontz D. Influence of 5,10-methylenetetrahydrofolate reductase polymorphism on whole-blood folate concentrations measured by LC-MS/ MS, microbiologic assay, and Bio-Rad radioassay. Clin Chem 2008;54:197-201.

55. Molloy AM, Mills JL, Kirke PN, Whitehead AS, Weir DG, Scott JM. Whole-blood folate values in subjects with different methylenetetrahydrofolate reductase genotypes: differences between the radioassay and microbiological assays. Clin Chem 1998;44: 186-8.

56. National Institute of Standards and Technology. Certificate of analysis, standard reference material 1955, homocysteine and folate in frozen human serum. April 2008. Available at: https:// www-s.nist.gov/srmors/certificates/1955.pdf. Accessed August 2016.

57. Thorpe SJ, Heath A, Blackmore S, Lee A, Hamilton M, O'Broin S, et al. International standard for serum vitamin $B 12$ and serum folate: international collaborative study to evaluate a batch of lyophilised serum for B12 and folate content. Clin Chem Lab Med 2007;45:380-6.

58. Blackmore S, Pfeiffer C, Hamilton MS, Lee A. Recoveries of folate species from serum pools sent to participants in the UK NEQAS Haematinics Scheme in February and March 2004. Clin Chim Acta 2005;355(Suppl):S459.

59. Pfeiffer CM, Fazili Z, McCoy L, Zhang M, Gunter EW. Determination of folate vitamers in human serum by stable-isotopedilution tandem mass spectrometry and comparison with radioassay and microbiologic assay. Clin Chem Lab Med 2004;50:423-32.

60. Blackmore S, Pfeiffer CM, Lee A, Fazili Z, Hamilton MS. Isotope dilution-LC-MS/MS reference method assessment of serum folate assay accuracy and proficiency testing consensus mean. Clin Chem Lab Med 2011;57:986-94.

61. Salter DN, Scott KJ, Slade H, Andrews P. The preparation and properties of folate-binding protein from cow's milk. Biochem J 1981;193:469-76.

62. Givas J, Gutcho S. pH dependence of the binding of folate to milk binder in radioassay of folates. Clin Chem 1975;21:427-8.

63. Wilson DH, Williams G, Herrmann R, Wiesner D, Brookhart P. Issues in immunoassay standardization: the Architect folate model for intermethod harmonization. Clin Chem 2005;51:684-7.

64. Owen WE, Roberts WL. Comparison of five automated serum and whole blood folate assays. Am J Clin Pathol 2003;120:121-6.

65. Gunter EW, Bowman BA, Caudill SP, Twite DB, Adams, MJ, Sampson EJ. Results of an international round robin for serum and whole blood folate. Clin Chem Lab Med 1996;42:1579-91.

66. Yeung L, Yang Q, Berry RJ. Contributions of total daily intake of folic acid to serum folate concentrations. J Am Med Assoc 2008;300:2486-7.

67. Pfeiffer CM, Johnson CL, Jain RB, Yetley EA, Picciano MF, Rader JI, et al. Trends in blood folate and vitamin B-12 concentrations in the United States, 1988-2004. Am J Clin Nutr 2007;86:718-27.

68. Hoey L, McNulty H, Askin N, Dunne A, Ward M, Pentieva K, et al. Effect of a voluntary food fortification policy on folate, related $B$ vitamin status, and homocysteine in healthy adults. Am J Clin Nutr 2007;86:1405-13.

69. Fazili Z, Sternberg MR, Paladugula N, Whitehead RD Jr, Chen $\mathrm{H}$, Pfeiffer CM. The loss of 5-methyltetrahydrofolate in human serum under suboptimal preanalytical conditions can only partially be recovered by an oxidation product. J Nutr 2014;144:1873-9.

70. Herbert V. Making sense of laboratory tests of folate status: folate requirements to sustain normality. Am J Hematol 1987;26:199-207.

71. Selhub J, Jacques PF, Dallal G, Choumenkovitch S, Rogers G. The use of blood concentrations of vitamins and their respective functional indicators to define folate and vitamin B12 status. Food Nutr Bull 2008;29(Suppl 2):S67-73.

72. de Benoist B. Conclusions of a WHO Technical Consultation on folate and vitamin B12 deficiencies. Food Nutr Bull 2008;29(Suppl 2):S238-44. 
73. Lacher DA, Hughes JP, Carroll MD. Biological variation of laboratory analytes based on the 1999-2002 National Health and Nutrition Examination Survey. National health statistics reports; no. 21. Hyattsville, MD: National Center for Health Statistics. 2010. Available at: https://www.cdc.gov/nchs/data/nhsr/ nhsr021.pdf. Accessed August 2016.

74. Braga F, Panteghini M. Generation of data on within-subject biological variation in laboratory medicine: an update. Crit Rev Clin Lab Sci 2016;53:313-25.

75. Horne III. Nutritional deficiences. In: Rodgers GP, Young NS, editors. Hematology in clinical practice, 3rd ed. Philadelphia: Lippincott, Williams and Wilkins, 2005:11-8.

76. Hao L, Yang QH, Li Z, Bailey LB, Zhu JH, Hu DJ, et al. Folate status and homocysteine response to folic acid doses and withdrawal among young Chinese women in a large-scale randomized double-blind trial. Am J Clin Nutr 2008;88:448-57.

77. Lang T; The Association for Clinical Biochemistry and Laboratory Medicine (ACB). National minimum re-testing interval project. Prepared for the Clinical Practice Group of the ACB and supported by the Royal College of Pathologists, 2013. Available at: http://www.acb.org.uk/docs/default-source/guidelines/acbmri-recommendations-a4-computer.pdf. Accessed August 2016.

78. Raiten DJ, Fisher KD. Assessment of folate methodology used in the Third National Health and Nutrition Examination Survey (NHANESIII, 1988-1994). J Nutr 1995;125:1371S-98S.

79. Dati F. The new European Directive on in vitro diagnostics. Clin Chem Lab Med 2003;41:1289-98.

80. Panteghini M. Implementation of standardization in clinical practice: not always an easy task. Clin Chem Lab Med 2012;50:1237-41.

81. Ferraro S, Mozzi R, Panteghini M. Revaluating serum ferritin as a marker of body iron stores in the traceability era. Clin Chem Lab Med 2012;50:1911-6.

82. Ferraro S, Mozzi R, Panteghini M. Tracing a roadmap for vitamin B12 testing using the health technology assessment approach. Clin Chem Lab Med 2014;52:767-77.

83. Eichholzer M, Tonz 0, Zimmermann R. Folic acid: a public-health challenge. Lancet 2006;367:1352-61.

84. Ryan AA. Medication compliance and older people: a review of the literature. Int J Nurs Stud 1999;36:153-62.
85. Smith AD, Refsum H, Selhub J Rosenberg IH. Decision on folic acid fortification in Europe must consider both risks and benefits. Br Med J 2016;352:i734.

86. Committee on Aspects of Food Policy. Folic acid and the prevention of disease. Report on health and social subjects. Stationery Office: London, 2000. Available at: www.worldcat.org/title/ folic-acid-and-the-prevention-of-disease. Accessed August 2016.

87. Food Standards Agency. Board reaches conclusion on folic acid. 2002. Available at: www.food.gov.uk/news/newsarchive/2002/ may/62488. Accessed August 2016.

88. Troen AM, Mitchell B, Sorensen B, Wener MH, Johnston A, Wood $B$, et al. Unmetabolized folic acid in plasma is associated with reduced natural killer cell cytotoxicity among postmenopausal women. J Nutr 2006;136:189-94.

89. Khoshnood B, Loane M, de Walle H, Arriola L, Addor MC, Barisic I, et al. Long term trends in prevalence of neural tube defects in Europe: population based study. Br Med J 2015;351:h5949.

90. McLean E, de Benoist B, Allen LH. Review of the magnitude of folate and vitamin B12 deficiencies worldwide. Food Nutr Bull 2008;29(Suppl 2):S38-51.

91. Bailey RL, Mills JL, Yetley EA, Gahche JJ, Pfeiffer CM, Dwyer JT, et al. Unmetabolized serum folic acid and its relation to folic acid intake from diet and supplements in a nationally representative sample of adults aged $60 \mathrm{y}$ in the United States. Am J Clin Nutr 2010;92:383-9.

92. Taruscio D. Folic acid: from research to public health practice. Rapporti ISTISAN 04/26. December 2004. Available at: www.iss.it/ binary/publ/publi/0426.1106232628.pdf. Accessed August 2016.

93. Mantovani A, Stazi AV, Taruscio D. Gene-environment interactions: folates and congenital malformations. Rapporti ISTISAN 02/26. 2002. Available at: www.iss.it/binary/cnmr4/ cont/0226_2002.pdf. Accessed August 2016.

94. Scientific Opinion on Dietary Reference Values for Folate. European Food Safety Authority (EFSA), Parma, Italy. Available at: https://www.efsa.europa.eu/sites/default/files/.../140722. pdf. Accessed August 2016.

95. Pelloso M, Basso D, Padoan A, Fogar P, Plebani M. Computerbased-limited and personalised education management maximise appropriateness of vitamin D, vitamin B12 and folate retesting. J Clin Pathol 2016;69:777-83. 